\title{
Energy Efficiency of Sustainable Renewable Microgrids for Off-Grid Electrification
}

\author{
Oluleke Babayomi \\ Shandong University \\ Jinan 250061, China \\ oluleke.babayomi@mail.sdu.edu.cn
}

\author{
Tobi Shomefun \\ Covenant University \\ Ota 112212, Nigeria \\ tobi.shomefun@covenantuniversity.edu.ng
}

\author{
Zhenbin Zhang* \\ Shandong University \\ Jinan 250061, China \\ zbz@sdu.edu.cn
}

\begin{abstract}
Energy efficiency (EE) has a key role to play in the rate of electrification towards decreasing energy poverty around the world. It has benefits to electrified urban and rural areas, as well as off-grid communities. Therefore, in this paper, we explore using empirical data, the impact of EE (as a form of demandside management) on the adoption of renewable microgrids for off-grid electrification in Sub-Saharan Africa. The study shows that improvements in the energy efficiency of commercial and residential appliances will optimize the availability of existing power resources, creating more access to underserved areas. An EE-centric power distribution model will also lead to higher value per energy served to under-served communities through renewable microgrids.
\end{abstract}

Index Terms-Energy efficiency, Energy poverty, Microgrid, Off-grid electrification, Sustainability

\section{INTRODUCTION}

Energy efficiency (EE) is an often ignored catalyst of energy access. For this reason, it has been called the world's first fuel by the International Energy Agency (IEA) [1]. However, EE falls within a broad scope of energy management techniques.

Energy management refers to the entire processes and methodologies applied to the optimal performance of the entire electrical energy system: from generation, through transmission and distribution, right to the loads [2]. The classical power system has advanced techniques for optimization of generation, transmission and distribution. However, in more recent times, attention has been focused on the optimal management at the consumers' end. The overall means of achieving energy management of the load is called the demand side management (DSM). There are five classes of DSM techniques [2], [3]:

The corresponding author of this work is Zhenbin Zhang. This work is financially supported in part by the Shandong Provincial Key Research and Development Program (Major Scientific and Technological Innovation Project NO.2019JZZY020805), in part by the National Distinguished Expert (Youth Talent) Program of China (31390089963058), in part by the General Program of National Natural Science Foundation of China (51977124), in part by the Shandong Natural Science Foundation (ZR2019QEE001).

978-1-7281-6746-6/20/\$31.00 @2020 IEEE energy efficiency (EE), energy conservation (EC), time of use (TOU), demand response (DR) and spinning reserve (SR).

$\mathrm{EE}$ aims to produce an equivalent level of service, while improving performance through the elimination of losses in the electro- mechanical/chemical system. This results in an effective reduction of energy consumption by the system being optimized. The processes required in EE result in permanent changes to the design of the electrical device, accompanied with energy and emission savings [2].

Energy conservation achieves the objective of energy management through the alteration of human habits and behavior, without any strict requirement of maintaining the previous level of service from the electrical device. These changes may involve intentional decisions to use, for instance, less airconditioning in a room when natural cooling via ventilation is possible.

Time of use tariffs introduce an additional penal charge for the use of electricity at particular time bounds within the day, for instance during expected evening peak loads periods. Market demand response is an interplay between the market demand trading of power and physical DR when some parts of the power system have downtimes due to faults or scheduled maintenance. Spinning reserve is the capacity of the power generators which is made available and unloaded to enable the online synchronous machines respond dynamically to contingencies [5]. The availability of power system SR enables rapid primary and secondary responses to frequency changes arising from increase or decrease in power demand. Through DSM, loads can be designed to automatically act as virtual power plants and use less energy whenever there is a drop in frequency.

The characteristic of DSM to modify load demand creates a less-costly alternative for meeting the growing demand of electricity in electrified communities. It costs less to implement DSM than to install new generation and distribution infrastructure. This benefit also provides a means of saving the cost of electrifying isolated communities that are not yet connected to the grid. Nonetheless, DSM does not always result in an 


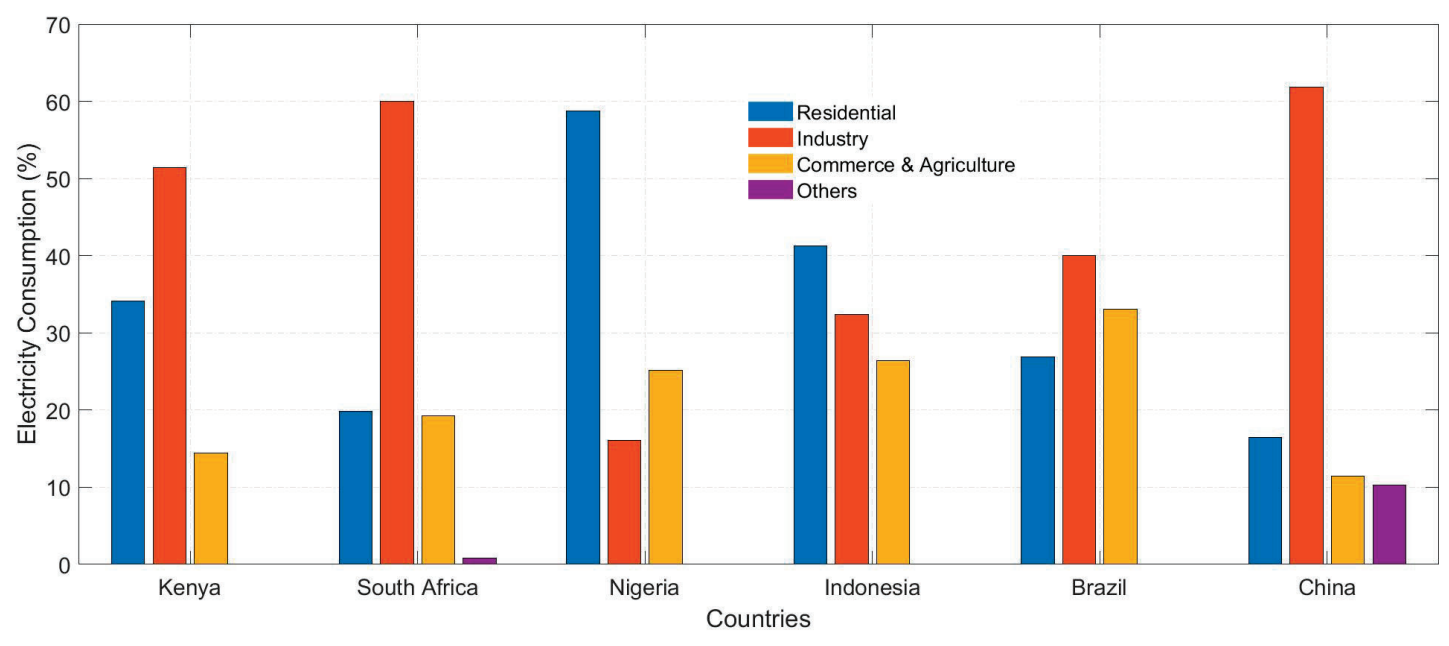

Fig. 1. Total electricity consumption by economic sectors (2017) [4].

overall reduction in energy demand as a result of the rebound effect [6] This means that consumers who experience cost savings in energy efficient devices can expend the savings directly or indirectly in energy-consuming activities, which maintain their overall energy consumption at the previous level of demand. EE has been shown to be an important factor in the acceleration rate of adoption of renewable microgrids for energy access at off-grid locations [7]. Therefore, in this paper, the focus is the impact of EE as a form of DSM on the adoption of renewable microgrids for off-grid electrification in Africa.

\section{Factors For Sustainable OfF-GRID REnEwABLe MICROGRIDS}

In present times, while MGs are being increasingly adopted across the world, the energy sources that power them are still composed of a significant level of carbon-based generation. Studies have shown that the optimal cost dispatch is optimal for a hybrid combination of energy sources, rather than the use of only one energy resource [8]. These hybrid generators are usually applied to power commercial, community, educational and remote microgrids [9].

Out of the estimated 1.3 billion people who have no access to electricity on Earth, more than 600 million are resident in Sub-Saharan Africa [10]. In addition, with an average household electrification rate of $42 \%$, this region also has the lowest access to power globally [11]. This backdrop spurred aidgiving organizations and developed nations to prod developing countries, especially in Sub-Saharan Africa and South Asia to look to the development of microgrids to boost electricity access of rural communities in their jurisdictions. Since rural dwellers are at least $70 \%$ of the entire population in a country like Nigeria [12], microgrids offer a promising solution to the short-term electrification of under-served communities around the world, where the power grid is yet to reach.

Nonetheless, in spite of extensive work done on the implementation of microgrids in developing countries, a new

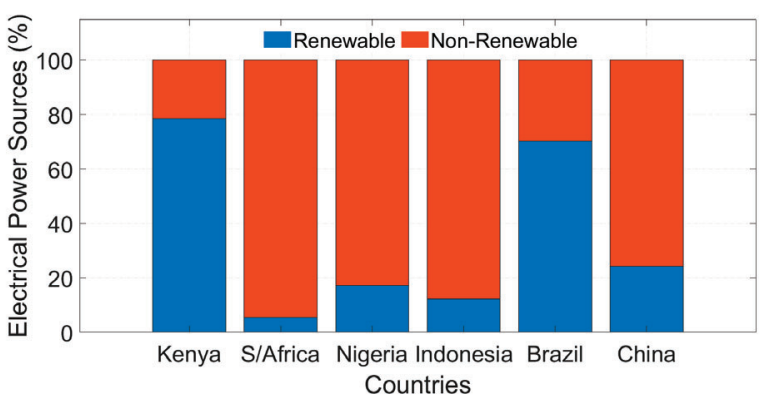

Fig. 2. Electricity generation from renewable and non-renewable sources [14].

narrative is emerging. Several microgrid projects are not living up to their potential. There is a growing reportage of high failure rates of recently commissioned projects that litter the terrains of poorly electrified communities. This implies that there is void in several areas including regulation, monitoring, technical competence, community ownership and control of projects and so on. The important composition for viable implementation models for community remote microgrids in West, South and East Africa, based on lessons learned from case studies are outlined in [12], and these results are summarized in Table I. The study highlights that sustainability of electrification through microgrids is hinged upon a robust model that includes community commercial ownership, economics, technology, environment, local policy and politics. A variant of this model is in use by the IEEE Smart Village, through Three Pillars, namely, electrification, education, and entrepreneurship. They have identified that the business model contributes $80 \%$ of the success of funded electrification entrepreneurs towards a sustainable scalable enterprise [13].

\section{ENERGy CONSUMPTION AND ELECTRIFICATION IN SUB-SAHARAN AFRICA}

Using Nigeria as a case study in Fig. 1, and comparing with five other developing economies, Kenya, South Africa, 
TABLE I

Summary of Model for Successful Sustainable OfF-GRID Renewable Microgrid.

\begin{tabular}{ll}
\hline Model Composition & Details \\
\hline Community Commercial Ownership & $\checkmark$ Effective Community Participation. \\
& $\checkmark$ Clearly Defined Commercial/Community Ownership. \\
& $\checkmark$ Security for Energy Infrastructure. \\
& $\checkmark$ Public Energy Literacy and Advocacy. \\
& $\checkmark$ Viable Commercial Microgrid Model. \\
& $\checkmark$ Government Cash Guarantees and Low-Tax Import. \\
& $\checkmark$ Microfinance and Business Capacity Development. \\
& $\checkmark$ Political and Economic Instability Guarantee and Incentives. \\
& $\checkmark$ Government-led Oversight and Standardization. \\
& $\checkmark$ Use of Quality Certified Equipment and Components. \\
& $\checkmark$ Leverage Technology to improve energy forecast accuracies. \\
& $\checkmark$ Engage Engineers and Technologists with A Track Record of Professionalism. \\
& \\
Technology & $\checkmark$ Local Energy Resource Mapping Data. \\
& $\checkmark$ Energy Impact Assessment Reports. \\
& $\checkmark$ Tariff Subsidy Regulations. \\
Policy and Political Factors & $\checkmark$ Grid-Creep Protection Policy. \\
& $\checkmark$ Invigorated and Empowered Quality Control Task Force. \\
& $\checkmark$ Better Skilled and Up-to-date Power and Energy Technocrats. \\
\hline
\end{tabular}

TABLE II

ELECTRIFICATION RATES IN SUB-SAHARAN AFRICA.

\begin{tabular}{lllll}
\hline $\begin{array}{l}\text { Region/ } \\
\text { Country }\end{array}$ & Kenya & $\begin{array}{l}\text { South } \\
\text { Africa }\end{array}$ & Nigeria & $\begin{array}{l}\text { Sub- } \\
\text { Saharan } \\
\text { Africa }\end{array}$ \\
\hline Overall electrification rate (\%) & 75 & 95 & 60 & 45 \\
Urban electrification rate (\%) & $>95$ & $>95$ & 86 & 74 \\
Rural electrification rate (\%) & 66 & 92 & 34 & 26 \\
\hline
\end{tabular}

Indonesia, Brazil and China. From latest available data (for 2017) got from IEA [4], the total final electricity consumption (less grid losses and energy industry own use) for each is, 8.46 TWh (Kenya), 25.77 TWh (Nigeria), 194.46 TWh (South Africa), 223.31 TWh (Indonesia), 498.51 TWh (Brazil) and 5,581.08 TWh (China). In addition, Fig. 2 reveals that data Kenya and Brazil generate a large percentage of electrical power from renewable sources, namely geothermal and largehydro respectively.

Among all these countries, Nigeria's residential electricity consumption has the highest percentage (about 60\%), China's industrial consumption is highest $(62 \%)$ and Brazil's commercial and agricultural use of grid-electricity is the greatest percentage $(33 \%)$. Nigeria's annual total energy consumption is $116.5 \mathrm{Mtoe}$, and this is sourced from biofuels and waste $(85.3 \%)$, oil products $(10.2 \%)$, natural gas $(2.7 \%)$, with less than $2 \%$ supplied by electricity. $78 \%$ of this total value is used for residential purposes of heating and cooking, while $16 \%$ is used by industry and transportation. Furthermore, data from the IEA indicates that total electricity annual electricity consumption for Nigeria is about $17.5 \mathrm{GWh}$, with residential and industrial applications accounting for 58\% and 16\% respectively.
Furthermore, the electrification rates for the top three economies in Sub-Saharan Africa, Nigeria, South Africa and Kenya, as seen in Table II indicate that South Africa and Kenya have the best electrification progress of $95 \%$ and $75 \%$ respectively, while Nigeria lags behind at $60 \%$.

\section{Energy SAVIngs in AC/DC Distribution AND BUILDINGS}

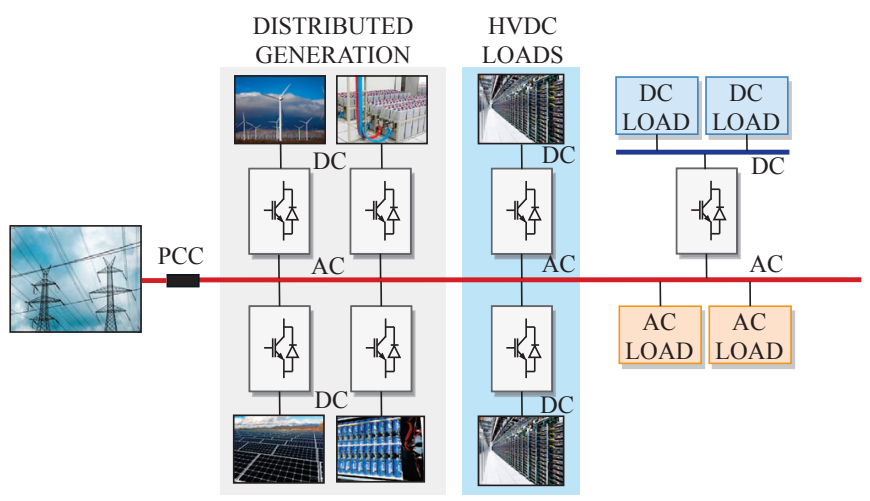

Fig. 3. Microgrid with AC distribution.

The conventional power system is AC-based. However, in the light of emerging microgrids with increasing distributed generation and buildings with high number of DC loads, the discussion on the comparison of AC and DC distribution has come to the fore. Fig. 3 illustrates the main components of an AC microgrid, along with converters which transform power for DGs and DC connected loads. On the other hand, Fig. 4 shows the interconnection of a microgrid with distribution of power in low voltage DC (LVDC). In this case, as shown, a 


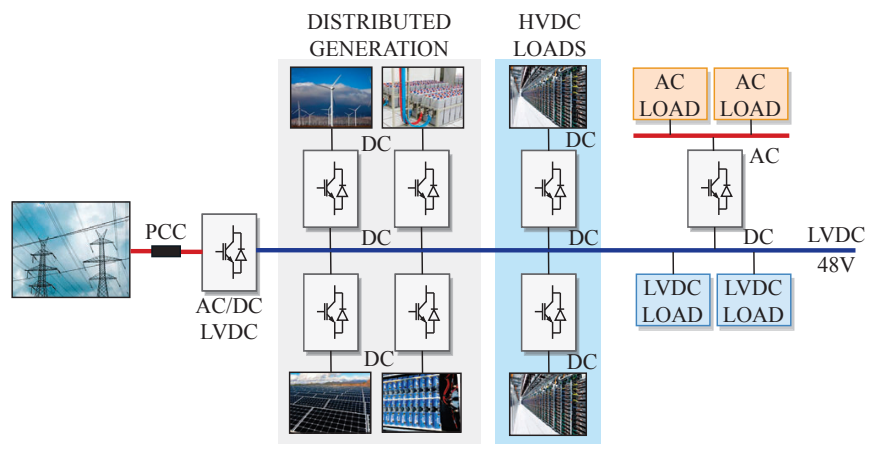

Fig. 4. Microgrid with low voltage DC distribution.

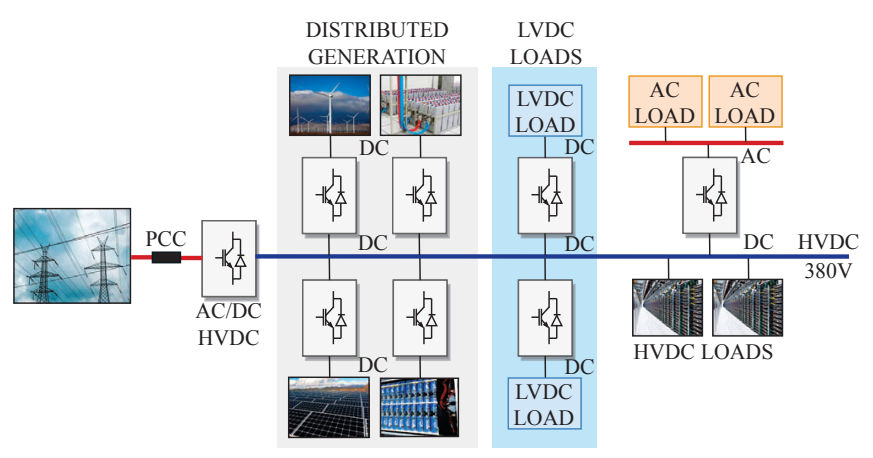

Fig. 5. Microgrid with high voltage DC distribution.

converter does step-down of grid voltage to $48 \mathrm{~V}$ DC, and DC loads are directly connected to the line. However, AC loads are connected through an inverter as shown. Finally, Fig. 5 is a case where the power distribution within the microgrid is distributed through a high voltage DC (HVDC) line of $380 \mathrm{~V}$.

In the case of LVDC, within a commercial building, it has been shown that energy savings over AC distribution can be at least $12 \%$. On the other hand, HVDC has a potential for energy savings reaching up to $18 \%$ over AC distribution [15]. These results are for zero-net energy (ZNE) buildings. Thus, while DC has higher efficiency within buildings, its advantages for distribution power networks remains inconclusive [16].

\section{ENERGY EFFICIENCY IMPACTS ON OFF-GRID ELECTRIFICATION}

\section{A. Commercial Appliances in Off-grid Electrification}

Table III, shows the daily energy consumption of appliances used at a commercial office at an off-grid site. These data are extrapolations from reported experimental results in [14]. All appliances have a daily working time of 8 hours, except fans, for which 4 hours was applicable. From the results DCpowered appliances have $25 \%$ total less energy use than $\mathrm{AC}$ appliances. Thus, this makes a case for DC microgrids in rural electrification. The results for tests on phone chargers over a 3 hour period is shown in Fig. 6, indicating the higher efficiency of the DC/DC converter over AC/DC charger. In addition, considering that income level is low in the target areas, savings in energy expense will create a significant improvement in
TABLE III

EXPERIMENTAL RESULTS OF EFFICIENCY AND TOTAL DAILY COMMERCIAL ENERGY CONSUMPTION.

\begin{tabular}{llllll}
\hline Devices & $\begin{array}{l}\text { AC Energy AC Mode } \\
\text { Consumed } \\
(\mathrm{Wh})\end{array}$ & $\begin{array}{l}\text { Efficiency } \\
(\%)\end{array}$ & $\begin{array}{l}\text { DC Energy DC Mode } \\
\text { Consumed } \\
(\mathrm{Wh})\end{array}$ & $\begin{array}{l}\text { DC Energy } \\
\text { Eficiency }\end{array}$ & $\begin{array}{l}\text { Savings } \\
\text { (Wh) }\end{array}$ \\
\hline $\begin{array}{l}\text { Laptop } \\
\text { Phone }\end{array}$ & 130.00 & 87.45 & 97.50 & 91.70 & 32.50 \\
Charger & 166.40 & 71.34 & 124.80 & 81.00 & 41.60 \\
Fan & 148.57 & 80.79 & 111.43 & 98.88 & 37.14 \\
\hline Total & 444.97 & - & 333.73 & - & 111.24 \\
\hline
\end{tabular}

disposable income for better standard of living. In addition, for commercial enterprises in such locations, lower cost of energy improves the affordability of their goods and services, resulting in higher patronage. This model has already been deployed by Mera Gao Power [17] in Uttar Pradesh State, India. Therefore, it is recommended that, with the cooperation of national energy agencies, more effort be applied towards higher scale of deployment of DC MGs in off-grid electrification in locations where the main grid has a low likelihood of being extended to in the future. These can apply where the users are high-density and within relatively close proximity, so that distribution losses (at high DC voltage) are minimized. Nonetheless this can be economically viable where the grid is expected to reach the community of interest, either in the long-term or never at all. This would provide sufficient time for recovery of investment by the DG developer. Otherwise, should the grid-arrival be expected to reach the community in the medium term, and solar home systems would be more appropriate. Considering the fact that $30 \%$ of energy savings results from residential energy efficiency efforts [18], Nigeria for instance can recover at least $4.54 \mathrm{TWh}$ of electricity annually, which represents $14.31 \%$ of her present annual energy generated (31.77 TWh).

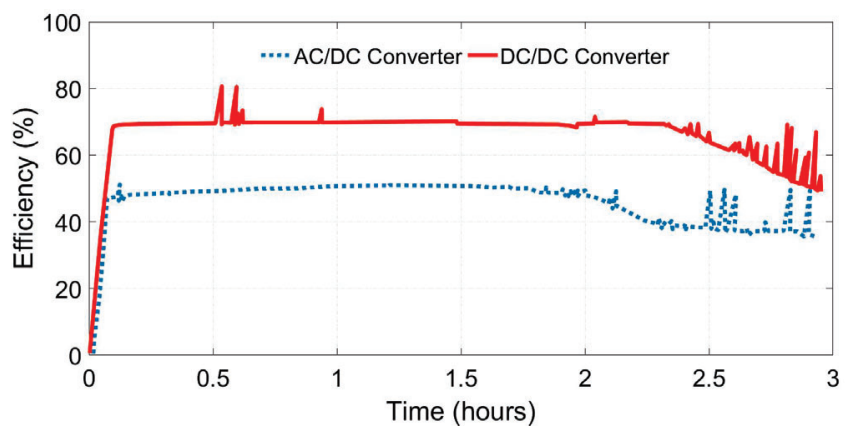

Fig. 6. Efficiency tests on DC/DC and AC/DC phone chargers [14].

\section{B. Residential Off-grid Electrification}

Fig. 7 illustrates an example of the benefits of energy efficiency to solar home systems (SHS) in residential off-grid electrification. The base case is that of a $25 \mathrm{~W}$ incandescent lighting load (200 - 300 lumens) in a residential stead, which is powered by $24 \mathrm{~V}$ DC from a $40 \mathrm{Wp}$ solar panel complemented with battery of 70 Ah capacity. This system 

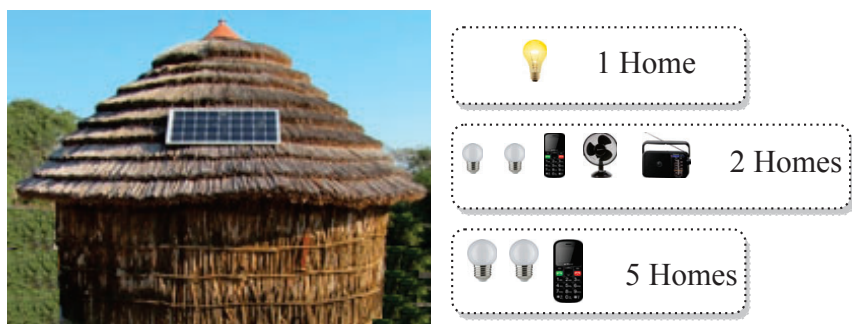

Fig. 7. Effect of energy-efficient appliances in residential off-grid home.

would only be able to deliver energy for 7 hours, assuming a $10 \%$ discharge limit on the battery. The second scenario shows that the same consumption of 7Ah can power two homes each with additional fan and radio if these extra loads are energized for 5 hours and 3 hours respectively. The final scenario shows that replacing the load with highly efficient LED lighting load results in the same energy consumption powering 2 lights and a phone charging unit per home 5 homes (same lighting effect per bulb) for the same daily duration. This shows the effect of added service and comfort that results from energy efficient residential appliances in SHS.

\section{CONCLUSION}

From this study, we have shown that, although the conventional means of increasing energy access is to increase investment in electrical power plants, this route could decelerate the electrification of Sub-Saharan Africa. This study has shown empirically, that energy efficiency offers significant returns for both commercial and residential microgrids in offgrid electrification. In particular, while DC distribution within buildings has higher energy savings than AC distribution for zero-net energy buildings, HVDC has even more promising gains.

\section{REFERENCES}

[1] R. Murray-Leach, The World's First Fuel: How energy efficiency is reshaping global energy systems. Energy Efficiency Council, Melbourne., 2019.

[2] P. Palensky and D. Dietrich, "Demand side management: Demand response, intelligent energy systems, and smart loads," IEEE Transactions on Industrial Informatics, vol. 7, no. 3, pp. 381-388, 2011.

[3] F. Boshell and O. P. Veloza, "Review of developed demand side management programs including different concepts and their results," in 2008 IEEE/PES Transmission and Distribution Conference and Exposition: Latin America, 2008, pp. 1-7.

[4] International Energy Agency, "World energy outlook-2019," 2019, https://www.iea.org/reports/sdg7-data-and-projections, Last accessed on 2020-05-21.

[5] M. Q. Wang and H. B. Gooi, "Spinning reserve estimation in microgrids," IEEE Transactions on Power Systems, vol. 26, no. 3, pp. 1164$1174,2011$.

[6] L. Ryan and N. Campbell, Spreading the net: the multiple benefits of energy efficiency improvements. OECD, 2012.

[7] T. W. Bank, EA+EE: Enhancing the world bank's energy access investments through energy efficiency. World Bank, 2015.

[8] B. Zhou, D. Xu, C. Li, Y. Cao, K. W. Chan, Y. Xu, and M. Cao, "Multiobjective generation portfolio of hybrid energy generating station for mobile emergency power supplies," IEEE Transactions on Smart Grid, vol. 9, no. 6, pp. 5786-5797, 2018.
[9] M. Bello and A. Maitra, "Lessons learned on protection coordination considerations within inverter-based microgrids," in 2018 IEEE PES/IAS PowerAfrica, 2018, pp. 539-544.

[10] U. E. I. Administration, International Energy Outlook; Technical Report. U.S. Energy Information Administration, Washington, DC, USA, 2016.

[11] D. Akinyele and R. Rayudu, "Strategy for developing energy systems for remote communities: Insights to best practices and sustainability," Sustainable Energy Technologies and Assessments, vol. 16, pp. 106-127, 2016.

[12] O. Babayomi and T. Okharedia, "Challenges to sub-saharan africa's renewable microgrid expansion - a cetep solution model," in 2019 IEEE PES/IAS PowerAfrica, 2019, pp. 617-621.

[13] R. S. Larsen and D. Estes, "Ieee smart village launches sunblazer iv and smart portable battery kits: Empowering remote communities," IEEE Systems, Man, and Cybernetics Magazine, vol. 5, no. 3, pp. 49-51, 2019.

[14] A. F. B. Santos, G. P. Duggan, C. D. Lute, and D. J. Zimmerle, "An efficiency comparison study for small appliances operating in dc and ac in minigrids," in 2018 IEEE Global Humanitarian Technology Conference (GHTC). IEEE, 2018, pp. 1-2.

[15] D. L. Gerber, V. Vossos, W. Feng, C. Marnay, B. Nordman, and R. Brown, "A simulation-based efficiency comparison of ac and de power distribution networks in commercial buildings," Applied Energy, vol. 210, pp. 1167-1187, 2018.

[16] F. Dastgeer, H. E. Gelani, H. M. Anees, Z. J. Paracha, and A. Kalam, "Analyses of efficiency/energy-savings of dc power distribution systems/microgrids: Past, present and future," International Journal of Electrical Power \& Energy Systems, vol. 104, pp. 89-100, 2019.

[17] D. Palit and S. Malhotra, "Energizing rural india using micro grids: the case of solar dc micro-grids in uttar pradesh state, india," in Third International Conference: Micro Perspectives for Decentralized Energy Supply, vol. Micro Perspectives for Decentralized Energy Supply: Proceedings of the International Conference,(Bangalore, India), 2015.

[18] R. Murray-Leach, The World's First Fuel: How energy efficiency is reshaping global energy systems. Energy Efficiency Council, Melbourne, 2019. 